\title{
Response to PD1 inhibition in conventional chondrosarcoma
}

\author{
Michael J. Wagner ${ }^{1,2^{*}}$ D, Robert W. Ricciotti ${ }^{3}$, Jose Mantilla ${ }^{3}$, Elizabeth T. Loggers ${ }^{1,2}$, Seth M. Pollack ${ }^{1,2}$ \\ and Lee D. Cranmer ${ }^{1,2^{*}}$
}

\begin{abstract}
Background: Chondrosarcoma is one of the most common malignant bone tumors in adults. Conventional chondrosarcoma represents around $85 \%$ of all chondrosarcomas and is notoriously difficult to treat with chemotherapy.

Case presentation: We describe a 67-year-old man with metastatic conventional chondrosarcoma who was treated with nivolumab. Treatment was discontinued after restaging showed increased tumor burden, which later proved to be pseudoprogression. The patient restarted nivolumab and continues to have a near complete response.

Conclusion: Conventional chondrosarcoma may be sensitive to checkpoint inhibitors. Further, this case demonstrates clearly the phenomenon of pseudo-progression in this disease, a factor that must be considered in the design of clinical trials and clinical care. This case supports additional study of immunomodulatory agents in this deadly disease.
\end{abstract}

Keywords: Chondrosarcoma, Immunotherapy, Sarcoma, Bone cancer

\section{Background}

Chondrosarcoma is one of the most common malignant bone tumors in adults [1]. Chondrosarcomas are further stratified into conventional, mesenchymal, dedifferentiated, and clear cell subtypes. Conventional chondrosarcoma represents around $85 \%$ of all chondrosarcomas and is notoriously difficult to treat with chemotherapy [1]. Mesenchymal chondrosarcoma is generally treated with Ewing sarcoma chemotherapy regimens, and dedifferentiated chondrosarcoma is treated as osteosarcoma. [1] Current guidelines of the National Comprehensive Cancer Network (NCCN, version 1.2018) indicate that "conventional chondrosarcoma (Grades 1-3) has no known standard chemotherapy options". Any efficacious systemic treatment would expand our current armamentarium for this difficult disease.

Immunotherapy has had enormous success in treating multiple cancer subtypes. Particular success has been seen with immune checkpoint inhibitors, which are now approved as standard therapy in melanoma [2, 3], lung $[4]$, genitourinary $[5,6]$, and cancers with microsatellite

\footnotetext{
*Correspondence: wagnermj@uw.edu; Icranmer@seattlecca.org ${ }^{1}$ Division of Medical Oncology, University of Washington School of Medicine, 825 Eastlake Avenue E, Seattle, WA 98109, USA

Full list of author information is available at the end of the article
}

instability [7] with an increasing number of indications as new data emerges. Initial studies in sarcoma have had mixed results. [8, 9] An early study of ipilimumab in synovial sarcoma was stopped due to lack of responses and poor accrual [10]. To date, little is understood about which sarcoma subtypes are most susceptible to immunotherapy and what drives the responses seen. Some of the studies of checkpoint inhibitors in sarcoma have included mesenchymal [11] and dedifferentiated chondrosarcomas $[8,11]$ with variable results, but these tumors are distinct from conventional chondrosarcoma in their general responsiveness to chemotherapy. [1] Conventional chondrosarcoma patients were not included in these studies.

Here we report a case of conventional chondrosarcoma with a near complete response after pseudo-progression on a checkpoint inhibitor. To our knowledge, this represents the first reported case of a dramatic response of a conventional chondrosarcoma to immunotherapy.

\section{Case presentation}

The patient is a 67-year-old man with a history of localized prostate cancer treated with prostatectomy. He initially presented with a $22 \mathrm{~cm}$ lytic mass of the distal femur. Core needle biopsy revealed grade 2 conventional 
chondrosarcoma. After resection, final pathology showed grade 3 conventional chondrosarcoma (Fig. 1a-b).

Nine months later, he developed innumerable, biopsyproven pulmonary metastases (Fig. 1c-d and Fig. 2a). Due to the general lack of efficacy of cytotoxic chemotherapy for conventional chondrosarcoma [1], the patient's inability to travel to participate in clinical trials and following extensive discussion with the patient, he initiated nivolumab $240 \mathrm{mg}$ (flat dose) intravenously every 2 weeks on a compassionate use basis. After 4 doses, the pulmonary nodules increased in size and number (Fig. 2b). Therapy was stopped, with plans to enroll in a clinical trial that was not available at our site at the time of nivolumab initiation.

Three months later, pre-trial CT scans revealed a near complete response in his pulmonary nodules, with most nodules resolving. One remaining index nodule previously measuring $16 \times 17 \mathrm{~mm}$ decreased to $5 \mathrm{~mm}$ and another measuring $11 \mathrm{~mm}$ decreased to $4 \mathrm{~mm}$. Rather than enrolling on trial, he reinitiated nivolumab therapy and continues with improvement in his few remaining pulmonary nodules (Fig. 2c).

We conducted analyses to understand the underlying pathogenetic mechanisms operative in this case. NextGen sequencing (NGS) revealed a mutation in exon 4 of $I D H 2$ and a variant of unknown significance in exon 11 of BRCA2. The tumor was microsatellite stable by sequencing and demonstrated no loss of expression of mismatch repair proteins (MLH1, MSH2, MSH6, and PMS2) when assessed by immunohistochemistry. PTEN expression was retained. The tumor did not express
PD-1 and was $1 \%$ positive (2+) for PD-L1. Tumor mutational burden was low (4 mutations/Mb).

\section{Discussion and conclusions}

Conventional chondrosarcomas are resistant to radiotherapy and chemotherapy. Because of this, there is no defined standard of care treatment for patients with unresectable or metastatic disease. Several mechanisms of have been proposed to explain the chemoresistance of the disease. Chondrosarcoma cell lines expressing MDR1 and P-glycoprotein are associated with anthracycline resistance. [12] Additional experiments link BCL-2 expression and $\mathrm{BCL}-2$-mediated resistance to apoptosis in the presence of chemotherapy. [13] The relative resistance of conventional chondrosarcoma is also attributed to the poor vascularity and high deposition of extracellular matrix in the tumors, and their relatively slow rate of growth. [14]

Efforts to identify druggable targets in chondrosarcoma have recently revealed recurrent mutations in $I D H 1$ and $I D H 2$, as was seen in the patient presented here. These are almost always found in chondrosarcoma cases associated with the Maffucci and Ollier syndromes [15], and in about half of other chondrosarcomas. [16] IDH is an enzyme in the Krebs cycle that normally catalyzes the conversion of isocitrate into alpha-ketoglutarate. Mutated IDH is able to catalyze conversion of $\alpha$-ketoglutarate into delta-2-hydroxyglutarate (2HG). Mutant $I D H 2$ leads to increased intracellular 2HG and hypermethylated DNA in mesenchymal cells, inhibiting their differentiation in a manner reversible by treatment with DNA-hypomethylating agents. [17]

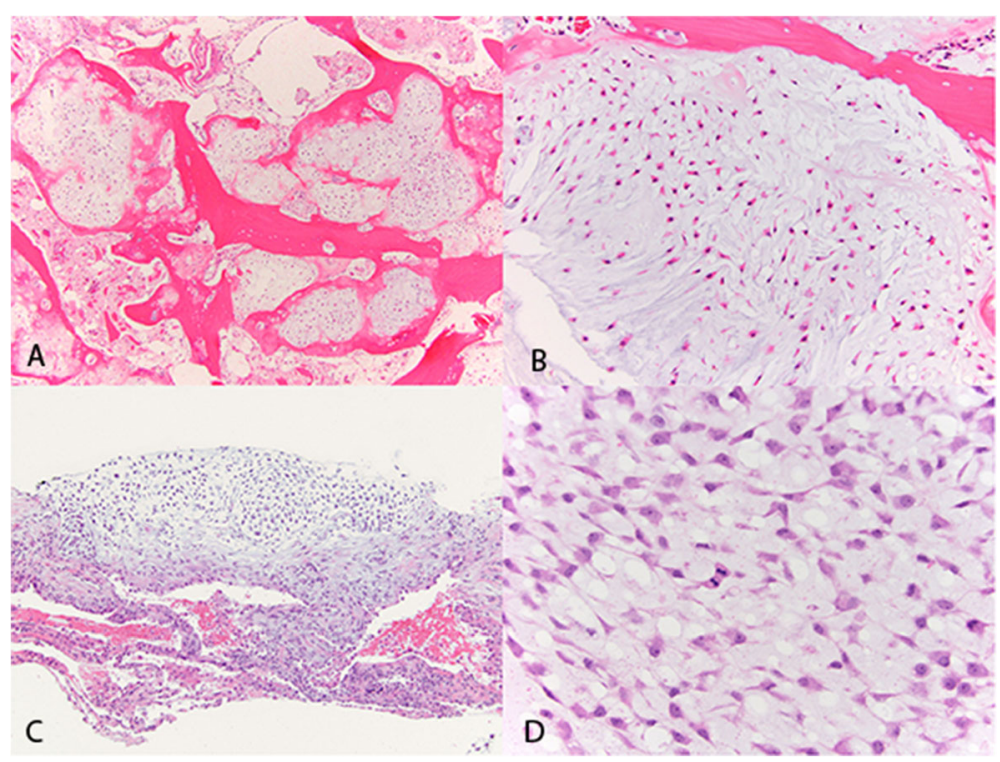

Fig. 1 Hematoxylin and eosin stained slides of the primary tumor at 40X magnification (a) and 100X magnification (b) and lung metastasis at 40X magnification (c) and 200X magnification (d) 


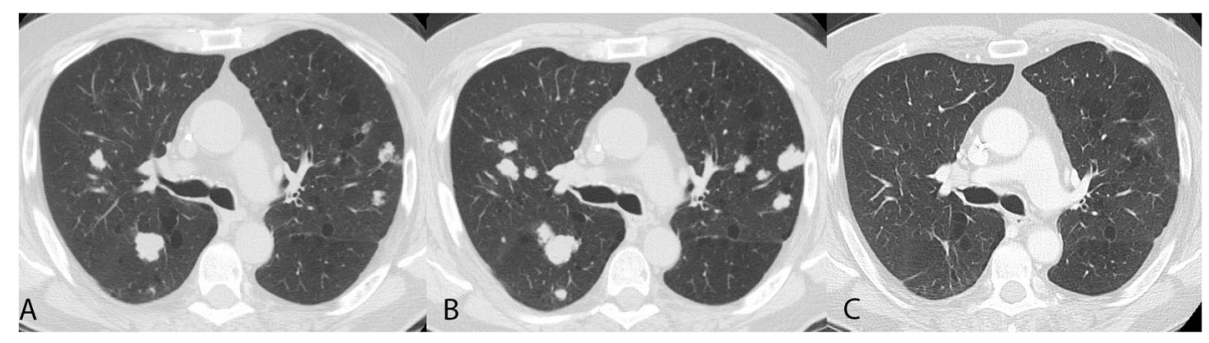

Fig. 2 Computerized tomography (CT) images of lung nodules. CT at time of initiation of nivolumab (a), 2 months after initiation of nivolumab (b) and 6 months after initiation of nivolumab (c)

There are conflicting data regarding the antitumor effects of direct IDH1 inhibition in chondrosarcoma. $[18,19]$ The clinical utility of this approach is being tested in trials for patients with IDH mutated cancers including chondrosarcoma (NCT02073994, NCT02746081). Interestingly, introduction of an activating IDH2 mutation in a syngeneic mouse model of glioma led to reduced levels of CXCL10 and suppression of cytotoxic T-cell recruitment to the tumor. [20] $I D H$ mutant gliomas also escape natural killer cell mediated lysis by epigenetic reprogramming that leads to downregulation of NKG2D ligand expression [21]. Given these findings in glioma, one might have expected this IDH 2 mutant chondrosarcoma to evade the immune system. However, this patient responded in spite of the presence of the $I D H 2$ mutation.

Other oncogenic pathways being studied as potential targets for chondrosarcoma include the PI3K-Akt-mTOR pathway, SRC pathway, and hedgehog pathway . [22] A small retrospective series of chondrosarcoma patients suggested clinical benefit with VEGFR2 inhibitors. [23] Additional efforts to identify targets by NGS have revealed recurrent alterations in TP53, ACVR2A, COL2A1, and YEATS2 in addition to the previously identified recurrent IDH mutations. [24]

Immunotherapy agents are increasingly demonstrating success in many cancer subtypes, and there have been preclinical suggestions that they may work in chondrosarcoma. An early report demonstrated that tumor specific immune responses against chondrosarcoma antigens is possible. [25] Cancer testis antigens (CTAs) such as NY-ESO-1, LAGE-1 s and PRAME are expressed in some sarcomas and may represent cancer-specific antigens to be used as targets for immunotherapies. A subset of chondrosarcomas express NY-ESO-1 or LAGE-1 $\mathrm{s}$ at baseline, and CTA expression is upregulated in chondrosarcoma cell lines after treatment with decitabine. [26] HMW-MAA is expressed in about $48 \%$ of chondrosarcomas and represents another potential antigen target for T-cells. [27] MAGE-A family CTAs are also expressed in chondrosarcoma [28] and can elicit lysis by cytotoxic T-lymphocytes. [29] In a rat model, depletion of intratumoral cytotoxic T-lymphocytes led to increased rates of tumor growth. [30] Collectively, these data suggest a role for immunomodulatory agents in chondrosarcoma.

In published clinical studies of immune checkpoint inhibitors in sarcoma, objective responses were seen in 2 patients with dedifferentiated chondrosarcoma. $[8,11]$ To our knowledge no published reports have included conventional chondrosarcoma patients treated with checkpoint inhibitors. One might consider a prospective study of single agent PD1 inhibition using immune criteria for response assessment. [31] The clear clinical benefit in this patient demonstrates that conventional chondrosarcoma may be sensitive to checkpoint inhibitors, and supports additional study of immunomodulatory agents in this disease. Further, this case demonstrates clearly the phenomenon of pseudo-progression in this disease, a factor that must be considered in the design of any clinical trials and clinical care.

\section{Abbreviations}

CTA: Cancer testis antigen; NGS: NextGen sequencing

\section{Funding}

MJW is funded by the QuadW Foundation-AACR Fellowship for Clinical/ Translational Sarcoma Research and Conquer Cancer Foundation/ Merck \& Co, Inc. Young Investigator Award.

\section{Authors' contributions}

MJW compiled and analyzed the clinical data and helped prepare the manuscript. RR and JM performed histological analysis of the tumor. EL and SP helped prepare the manuscript. LC is the primary oncologist for the patient reported, helped compile the data, and helped prepare the manuscript. All authors read and approved the manuscript.

\section{Consent for publication}

Informed consent was obtained from the patient prior to preparation of this case report.

\section{Competing interests}

The authors declare that they have no competing interests.

\section{Publisher's Note}

Springer Nature remains neutral with regard to jurisdictional claims in published maps and institutional affiliations.

\section{Author details}

${ }^{1}$ Division of Medical Oncology, University of Washington School of Medicine, 825 Eastlake Avenue E, Seattle, WA 98109, USA. ${ }^{2}$ Clinical Research Division, 
Fred Hutchinson Cancer Research Center, 1100 Fairview Ave N, Seattle, WA 98109, USA. ${ }^{3}$ Department of Pathology, University of Washington School of Medicine, 1959 NE Pacific St, Seattle, WA 98195, USA.

Received: 25 July 2018 Accepted: 18 September 2018

Published online: 25 September 2018

\section{References}

1. Wagner MJ, Livingston JA, Patel SR, Benjamin RS. Chemotherapy for bone sarcoma in adults. J Oncol Pract. 2016;12(3):208-16.

2. Larkin J, Chiarion-Sileni V, Gonzalez R, Grob JJ, Cowey CL, Lao CD, et al. Combined Nivolumab and Ipilimumab or Monotherapy in untreated melanoma. N Engl J Med. 2015:373(1):23-34.

3. Robert C, Schachter J, Long GV, Arance A, Grob JJ, Mortier L, et al. Pembrolizumab versus Ipilimumab in Advanced Melanoma. N Engl J Med. 2015;372(26):2521-32.

4. Garon EB, Rizvi NA, Hui R, Leighl N, Balmanoukian AS, Eder JP, et al. Pembrolizumab for the treatment of non-small-cell lung cancer. N Engl J Med. 2015;372(21):2018-28.

5. Powles T, Eder JP, Fine GD, Braiteh FS, Loriot Y, Cruz C, et al. MPDL3280A (anti-PD-L1) treatment leads to clinical activity in metastatic bladder cancer. Nature. 2014:515(7528):558-62.

6. Motzer RJ, Tannir NM, McDermott DF, Aren Frontera O, Melichar B, Choueiri TK, et al. Nivolumab plus Ipilimumab versus Sunitinib in advanced renal-cell carcinoma. N Engl J Med. 2018;378(14):1277-90.

7. Overman MJ, McDermott R, Leach JL, Lonardi S, Lenz HJ, Morse MA, et al. Nivolumab in patients with metastatic DNA mismatch repair-deficient or microsatellite instability-high colorectal cancer (CheckMate 142): an openlabel, multicentre, phase 2 study. Lancet Oncol. 2017;18(9):1182-91.

8. Tawbi HA, Burgess M, Bolejack V, Van Tine BA, Schuetze SM, Hu J, et al. Pembrolizumab in advanced soft-tissue sarcoma and bone sarcoma (SARC028): a multicentre, two-cohort, single-arm, open-label, phase 2 trial. Lancet Oncol. 2017.

9. D'Angelo SP, Mahoney MR, Van Tine BA, Atkins J, Milhem MM, Jahagirdar $B N$, et al. Nivolumab with or without ipilimumab treatment for metastatic sarcoma (Alliance A091401): two open-label, non-comparative, randomised, phase 2 trials. Lancet Oncol. 2018:19(3):416-26.

10. Maki RG, Jungbluth AA, Gnjatic S, Schwartz GK, D'Adamo DR, Keohan ML, et al. A pilot study of anti-CTLA4 antibody Ipilimumab in patients with synovial sarcoma. Sarcoma. 2013;168145:2013.

11. Paoluzzi L, Cacavio A, Ghesani M, Karambelkar A, Rapkiewicz A, Weber J, et al. Response to anti-PD1 therapy with nivolumab in metastatic sarcomas. Clin Sarcoma Res. 2016;6:24.

12. Wyman JJ, Hornstein AM, Meitner PA, Mak S, Verdier P, Block JA, et al. Multidrug resistance- 1 and p-glycoprotein in human chondrosarcoma cell lines: expression correlates with decreased intracellular doxorubicin and in vitro chemoresistance. J Orthop Res. 1999;17(6):935-40.

13. van Oosterwiik JG, Herpers B, Meijer D, Briaire-de Bruijn IH, Cleton-Jansen AM, Gelderblom H, et al. Restoration of chemosensitivity for doxorubicin and cisplatin in chondrosarcoma in vitro: BCL-2 family members cause chemoresistance. Ann Oncol. 2012;23(6):1617-26.

14. Gelderblom H, Hogendoorn PC, Dijkstra SD, van Rijswijk CS, Krol AD, Taminiau AH, et al. The clinical approach towards chondrosarcoma. Oncologist. 2008;13(3):320-9.

15. Amary MF, Damato S, Halai D, Eskandarpour M, Berisha F, Bonar F, et al. Ollier disease and Maffucci syndrome are caused by somatic mosaic mutations of IDH1 and IDH2. Nat Genet. 2011;43(12):1262-5.

16. Amary MF, Bacsi K, Maggiani F, Damato S, Halai D, Berisha F, et al. IDH1 and $\mathrm{IDH} 2$ mutations are frequent events in central chondrosarcoma and central and periosteal chondromas but not in other mesenchymal tumours. J Pathol. 2011;224(3):334-43.

17. Lu C, Venneti S, Akalin A, Fang F, Ward PS, Dematteo RG, et al. Induction of sarcomas by mutant IDH2. Genes Dev. 2013;27(18):1986-98.

18. Li L, Paz AC, Wilky BA, Johnson B, Galoian K, Rosenberg A, et al. Treatment with a small molecule mutant IDH1 inhibitor suppresses tumorigenic activity and decreases production of the Oncometabolite 2-Hydroxyglutarate in human Chondrosarcoma cells. PLoS One. 2015;10(9):e0133813.

19. Suijker J, Oosting J, Koornneef A, Struys EA, Salomons GS, Schaap FG, et al. Inhibition of mutant IDH1 decreases D-2-HG levels without affecting tumorigenic properties of chondrosarcoma cell lines. Oncotarget. 2015;6(14): 12505-19.
20. Kohanbash G, Carrera DA, Shrivastav S, Ahn BJ, Jahan N, Mazor T, et al. Isocitrate dehydrogenase mutations suppress STAT1 and CD8+ T cell accumulation in gliomas. J Clin Invest. 2017;127(4):1425-37.

21. Zhang X, Rao A, Sette P, Deibert C, Pomerantz A, Kim WJ, et al. IDH mutant gliomas escape natural killer cell immune surveillance by downregulation of NKG2D ligand expression. Neuro-Oncology. 2016;18(10):1402-12.

22. Polychronidou G, Karavasilis V, Pollack SM, Huang PH, Lee A, Jones RL. Novel therapeutic approaches in chondrosarcoma. Future Oncol. 2017;13(7):637-48.

23. Jones RL, Katz D, Loggers ET, Davidson D, Rodler ET, Pollack SM. Clinical benefit of antiangiogenic therapy in advanced and metastatic chondrosarcoma. Med Oncol. 2017:34(10):167.

24. Totoki Y, Yoshida A, Hosoda F, Nakamura H, Hama N, Ogura K, et al. Unique mutation portraits and frequent $\mathrm{COL} 2 \mathrm{~A} 1$ gene alteration in chondrosarcoma. Genome Res. 2014;24(9):1411-20.

25. Hiraki A, Ikeda K, Yoshino T, Kaneshige T, Kiura K, Kunisada T, et al. Tumorspecific cytotoxic T lymphocyte responses against chondrosarcoma with HLA haplotype loss restricted by the remaining HLA class I allele. Biochem Biophys Res Commun. 2001;286(4):786-91.

26. Pollack SM, Li Y, Blaisdell MJ, Farrar EA, Chou J, Hoch BL, et al. NYESO-1/ LAGE-1s and PRAME are targets for antigen specific T cells in chondrosarcoma following treatment with 5-Aza-2-deoxycitabine. PLoS One. 2012;7(2):e32165.

27. Schwab JH, Boland PJ, Agaram NP, Socci ND, Guo T, O'Toole GC, et al. Chordoma and chondrosarcoma gene profile: implications for immunotherapy. Cancer Immunol Immunother. 2009;58(3):339-49.

28. Lin C, Mak S, Meitner PA, Wolf JM, Bluman EM, Block JA, et al. Cancer/testis antigen CSAGE is concurrently expressed with MAGE in chondrosarcoma. Gene. 2002;285(1-2):269-78.

29. Bluman EM, Coulie PG, Xiaojuan S, Machan J, Lin C, Meitner PA, et al. Lysis of human chondrosarcoma cells by cytolytic $T$ lymphocytes recognizing a MAGE-A3 antigen presented by HLA-A1 molecules. J Orthop Res. 2007;25(5):678-84.

30. Simard FA, Richert I, Vandermoeten A, Decouvelaere AV, Michot JP, Caux C, et al. Description of the immune microenvironment of chondrosarcoma and contribution to progression. Oncoimmunology. 2017;6(2):e1265716.

31. Seymour L, Bogaerts J, Perrone A, Ford R, Schwartz LH. Mandrekar S, et al. IRECIST: guidelines for response criteria for use in trials testing immunotherapeutics. Lancet Oncol. 2017;18(3):e143-e52.

\section{Ready to submit your research? Choose BMC and benefit from:}

- fast, convenient online submission

- thorough peer review by experienced researchers in your field

- rapid publication on acceptance

- support for research data, including large and complex data types

- gold Open Access which fosters wider collaboration and increased citations

- maximum visibility for your research: over $100 \mathrm{M}$ website views per year

At $\mathrm{BMC}$, research is always in progress.

Learn more biomedcentral.com/submissions 